\title{
Design Options to Minimize Tritium Inventories at Savannah River
}

\author{
J. E. Klein ${ }^{\mathrm{a}}$, J. Wilson ${ }^{\mathrm{a}}$, K. J. Heroux ${ }^{\mathrm{a}}$, A. S. Poore ${ }^{\mathrm{a}}$, D. W. Babineau ${ }^{\mathrm{a}}$ \\ ${ }^{a}$ Savannah River National Laboratory, Aiken, SC, USA
}

\begin{abstract}
Large quantities of tritium are stored and processed at the Savannah River Site (SRS) Tritium Facilities. In many design basis accidents (DBAs), it is assumed the entire tritium inventory of the in-process vessels are released from the facility and the site for inclusion in public radiological dose calculations. Pending changes in public dose calculation methodologies are driving the need for smaller in-process tritium inventories to be released during DBAs. Reducing the in-process tritium inventory will reduce the unmitigated source term for public dose calculations and will also reduce the production demand for a lower inventory process. This paper discusses process design options to reduce in-process tritium inventories. A Baseline process is defined to illustrate the impact of removing or replacing La-Ni-Al alloy tritium storage beds with palladium (Pd) or depleted uranium (DU) storage beds on facility in-process tritium inventories. Elimination of La-Ni-Al alloy tritium storage beds can reduce in-process tritium inventories by over $1.5 \mathrm{~kg}$, but alternate process technologies may needed to replace some functions of the removed beds.
\end{abstract}

Keywords: Tritium; Hydride; Tritide; Aging; Tritium Storage

\section{Introduction}

The tritium supply for US defense program applications is part of an integrated program to ensure adequate supplies of tritium (and other nuclear materials) for current and future stockpile needs. Facilities such as the Savannah River Site (SRS) were constructed to produce tritium for defense programs. Development programs in the 1980's were initiated to reduce the size of tritium process systems through the use of metal hydride technology [1]. The hydride-based process systems were small enough to be affordably placed in inerted gloveboxes to minimize tritium releases to the environment [2]. The use of metal hydride technology also allowed elimination of many oil- and mercury-based pumps used for tritium processing and the delivery of tritium nearly free of $\mathrm{He}-3$ [3].

One of the metal hydrides developed for use in the tritium facilities was $\mathrm{LaNi}_{5-\mathrm{x}} \mathrm{Al}_{\mathrm{x}}$ ("LANAx") where $\mathrm{x}$ represents the atomic substitution of aluminum for nickel in the base $\mathrm{LaNi}_{5}$ alloy. The pressure-compositiontemperature (PCT) properties of the $\mathrm{La}-\mathrm{Ni}-\mathrm{Al}$ alloy can be altered by varying the amount of $\mathrm{Al}$ substituted for $\mathrm{Ni}$ in the alloy [4].

Tritium aging effects from storing tritium in La-Ni$\mathrm{Al}$ ("LANAx") based alloys have been studied [5]. The desire to perform tritium inventory measurements without removing tritium from a storage vessel, especially from a vessel with long-term tritium exposure, lead to the development of the In-Bed Accountability (IBA) or In-Bed Calorimetry (IBC) method for process hydride bed tritium inventory measurements [6].

As part of development efforts to modify the SRS tritium processes, one topic for examination is the reduction of in-process tritium inventories [7, 8]. Fig. 1 illustrates tritium aging effects on the PCT properties for $\mathrm{LaNi}_{4.25} \mathrm{Al}_{0.75}$ (LANA0.75); T/M is the tritium-to-metal ratio $(T / M)$, where $T$ is the number of tritium atoms and $\mathrm{M}$ is the number of metal atoms.

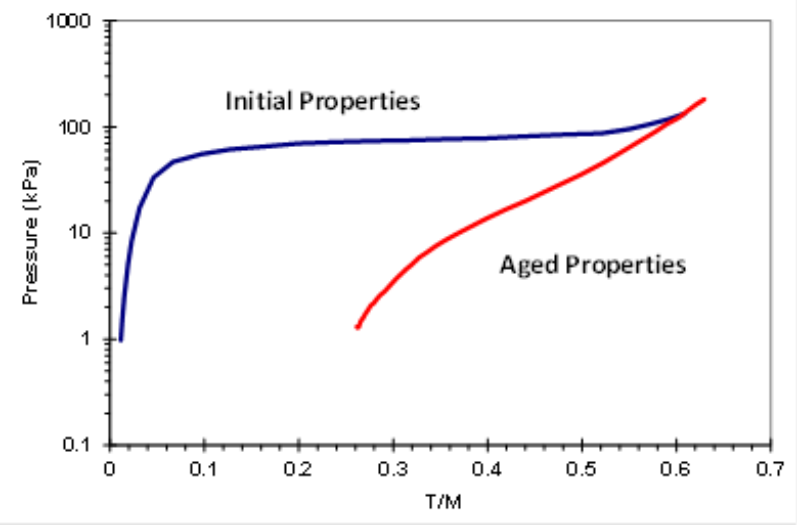

Fig. 1. Typical tritium aged LANA0.75 isotherm.

Fig. 1 illustrates "aged" LANA0.75 (the hydride exposed to tritium) where lower pressures and/or higher temperatures are needed to remove tritium from the hydride. Some tritium in the hydride is considered "trapped" since it cannot be removed under normal process conditions, but unfortunately is still considered releasable during design basis accidents (DBAs) for public dose calculations. Trapped tritium also increases the procurement/production costs since some process tritium needed is inaccessible for process operations. The purpose of this paper is to examine different process options and hydride technologies to reduce total and inaccessible in-process tritium inventories.

\section{Background}

For the purposes of this paper, comparisons will be made between storing tritium on LANA0.75, palladium (Pd), and depleted uranium (DU). He-3 is not

author's email: james.klein@srnl.doe.gov 
significantly retained in DU and has little impact on its PCT properties [9]. He-3 retention in $\mathrm{Pd}$ has a slight impact on PCT properties, but significantly less than for LANA0.75 [5]. For comparison purposes, it is assumed that only the PCT properties of LANA0.75 are impacted by tritium storage/exposure.

Fig. 2 illustrates the minimum and maximum storage inventories of a hydride material in terms of the $\mathrm{Q} / \mathrm{M}$ ratio, where $\mathrm{Q}$ is the sum of protium $(\mathrm{H})$, deuterium (D) and tritium $(\mathrm{T})$ atoms. The Useable Inventory of a hydride bed $(\Delta \mathrm{Q} / \mathrm{M})$ will be its maximum inventory, $\mathrm{Q} / \mathrm{M}_{\max }$, less its minimum inventory, $\mathrm{Q} / \mathrm{M}_{\min }$. These inventories can vary between "new" (absent tritium exposure) metal hydride material and tritium aged/ exposed materials, which are based on bed performance under process operating conditions. For this paper, only $\mathrm{Q} / \mathrm{M}_{\min }$ for the LANA0.75 will be assumed to vary as a result of tritium aging.

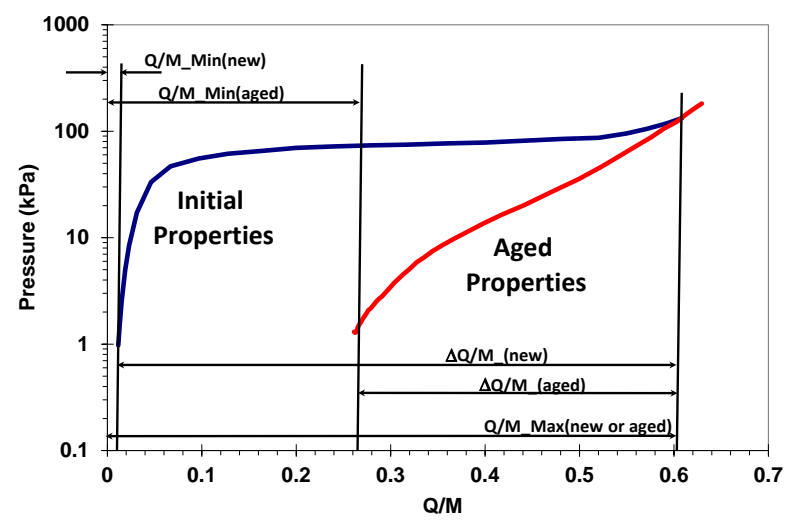

Fig. 2. LANA0.75 inventories

\section{Baseline process}

Fig. 3 illustrates the Baseline process to be evaluated for this paper. The gas input stream first goes through a series of separation and absorption processes before the tritium undergoes isotopic separation and is stored on a Product bed. The process analyzed is for illustration purposes only and does not imply current or projected facility inventories.

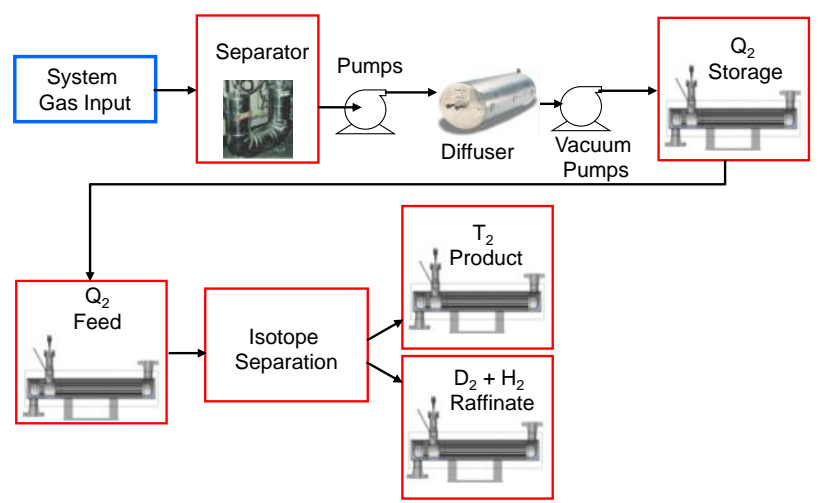

Table 1 contains some information for the Fig. 3 Baseline process for calculating initial tritium inventories. The Useable Inventories of the Storage and Feed beds were taken to be 1500 STP-L (standard liters of gas referenced to $0^{\circ} \mathrm{C}$ and 760 torr) each, the Separator bed to be $1 / 3^{\text {rd }}$ the inventory of a Storage bed (500 STP-L), and the Product bed to be 5000 STP-L. For calculation purposes, the mole fraction of tritium $\left(\mathrm{x}_{\mathrm{T}}\right)$ in the Separator, Storage, and Feed beds was assumed to be $50 \%$ tritium and that of a Product bed $100 \%$ tritium. The number of each bed type is also included in Table 1.

Table 1. Baseline process information.

\begin{tabular}{ccccc}
\hline & Separator & Storage & Feed & Product \\
\hline Hydride & $\mathrm{Pd}$ & $\begin{array}{l}\text { LANA } \\
0.75\end{array}$ & $\begin{array}{l}\text { LANA } \\
0.75\end{array}$ & LANA \\
& & 0.75 \\
$\mathrm{Q} / \mathrm{M}_{\min :}$ & 0.050 & 0.080 & 0.080 & 0.080 \\
new & & & & \\
$\mathrm{Q} / \mathrm{M}_{\min }:$ & 0.050 & 0.355 & 0.355 & 0.355 \\
aged & & & & \\
$\mathrm{Q} / \mathrm{M}_{\max }$ & 0.720 & 0.800 & 0.800 & 0.800 \\
$\Delta \mathrm{Q} / \mathrm{M}_{\text {New }}$ & 500 & 1500 & 1500 & 5000 \\
$(\mathrm{STP}-\mathrm{L})$ & 2 & 4 & 2 & 2 \\
$\#$ of Beds & 2 & $50 \% \mathrm{~T}$ & $50 \% \mathrm{~T}$ & $100 \% \mathrm{~T}$ \\
$\mathrm{x}_{\mathrm{T}}$ & $50 \% \mathrm{~T}$ & $50 \%$
\end{tabular}

Table 2 contains the mass of hydride materials needed to have new Useable Inventories of 500, 1500, and 5000 STP-L. For these calculations, the molecular weights for Pd, DU, and LANA0.75 were taken as 106.4, 238.06, and 408.66 grams per mole, respectively. The $\mathrm{Q} / \mathrm{M}_{\min }$ and $\mathrm{Q} / \mathrm{M}_{\max }$ values for DU were taken as 0.250 and 2.80 , respectively.

Table 2. Hydride mass (grams) for listed Useable Inventories.

\begin{tabular}{cccc}
\hline $\begin{array}{c}\Delta \mathrm{Q} / \mathrm{M}_{\text {New }} \\
(\mathrm{STP}-\mathrm{L})\end{array}$ & $\begin{array}{c}\mathrm{Pd} \\
(\mathrm{g})\end{array}$ & $\begin{array}{c}\text { DU } \\
(\mathrm{g})\end{array}$ & $\begin{array}{c}\text { LANA 0.75 } \\
(\mathrm{g})\end{array}$ \\
\hline 500 & 7,085 & 4,165 & 4,221 \\
1500 & 21,255 & 12,495 & 12,662 \\
5000 & 70,851 & 41,651 & 42,205
\end{tabular}

\section{Process tritium inventories}

Using the mass of hydride from Table 2 along with hydride $\mathrm{Q} / \mathrm{M}_{\min }$ and $\mathrm{Q} / \mathrm{M}_{\max }$ values, minimum and maximum bed inventories can be calculated. For new 1500 STP-L Useable Inventory beds, Table 3 shows bed inventories and the reduced Useable Inventory for an aged LANA0.75 bed. Similar tables can be created for 500 and 5000 STP-L Useable Inventory beds.

Table 3. STP-L inventories for 1500 STP-L Useable Inventory beds.

\begin{tabular}{lccc}
\hline & Pd & DU & LANA 0.75 \\
\hline $\mathrm{Q} / \mathrm{M}_{\max }:$ new & 1612 & 1647 & 1667 \\
$\mathrm{Q} / \mathrm{M}_{\min }:$ new & 112 & 147 & 167 \\
$\mathrm{Q} / \mathrm{M}_{\min }:$ aged & 112 & 147 & 740 \\
$\Delta \mathrm{Q} / \mathrm{M}_{\text {New }}$ & 1500 & 1500 & 1500 \\
$\Delta \mathrm{Q} / \mathrm{M}_{\text {Aged }}$ & 1500 & 1500 & 927
\end{tabular}

Fig. 3. Baseline process illustration 
To calculate in-process tritium inventories, the quantity of gas in each bed must be specified. To operate a batch process in a continuous mode, a pair of beds will need to be operated out-of-phase, e.g. one bed on-line and the other in regeneration mode. To calculate what is defined as the Operational Inventory, one-half of the beds in each process location will be at the minimum inventory of the bed while the other beds will be at the maximum inventory of the bed. For example, the contribution to Operational Inventory for new LANA0.75 Storage beds will be two beds at their minimum inventory (two-times 167 STP-L) plus two beds at their maximum inventory (two-times 1667 STPL): 3,668 STP-L. For $\mathrm{x}_{\mathrm{T}}$ equal to $50 \%$ tritium, the Operational Inventory for these four beds is $493 \mathrm{~g}$ tritium.

The Useable Inventory for the process will be defined as the sum of the Useable Inventories of all the individual beds in the process. For example, the Useable Inventory for four new LANA0.75 Storage beds is fourtimes 1500 STP-L: 6,000 STP-L or $807 \mathrm{~g}$ tritium. The maximum inventory for the Storage beds is four-times 1667 STP-L: 6668 STP-L or $897 \mathrm{~g}$ tritium.

\subsection{Baseline process inventories}

The tritium inventories for the Baseline process using the information from Table 1 and Table 2 are summarized in Table 4, where "Ops" is an abbreviation for Operational Inventory. The table shows the new minimum facility inventory as $0.444 \mathrm{~kg}$ tritium with a new Useable Inventory of $4.04 \mathrm{~kg}$. As the LANA0.75 beds age, the minimum facility inventory rises to $1.93 \mathrm{~kg}$ tritium while the Useable Inventory is reduced to 2.55 $\mathrm{kg}$.

\subsection{Reduced Bed process inventories}

One method to reduce the in-process tritium inventory is to reduce the number of hydride beds in the process. This option would rely on different technologies to replace some of the process functions supplied by the beds removed from the process. For example, the Separator beds and the Feed beds could be eliminated from the baseline process to produce a "Reduced Bed" process. For this process, all the process input gas could be processed through diffusers and the isotope separation feed gas could be supplied by a pump. The pros and cons of replacing hydride bed functions with other technologies will not be discussed other than its impact on tritium inventory.

The process inventories for the Reduced Bed process are shown in Table 5 which is a revised version of Table 4 with the contributions from the Separator beds and the Feed beds eliminated. The table shows the new minimum facility inventory as $0.389 \mathrm{~kg}$ tritium with a new Useable Inventory of $3.50 \mathrm{~kg}$. As the LANA0.75 beds age, the minimum facility inventory rises to $1.73 \mathrm{~kg}$ tritium while the Useable Inventory is reduced to 2.16 $\mathrm{kg}$.

\subsection{Alternate hydride process inventories}

The next comparison to the Baseline process will be to examine the impact on facility inventory by replacing LANA 0.75 beds with alternate hydride material beds, either Pd or DU beds, which have less tritium aging effects. Direct replacement of LANA0.75 beds with Pd or DU beds with the mass of materials specified in Table 2 (e.g., the same initial Useable Inventory) would produce results similar to those presented in Table 4 for new LANA 0.75 beds and are not shown.

\subsection{Reduced Useable Inventory process inventories}

Another comparison to the Baseline process is to use $\mathrm{Pd}$ and/or DU beds that have Useable Inventories equal to that of aged LANA0.75 beds. The concept is if the facility can operate with aged LANA0.75 beds (with a reduced Useable Inventory), a process designed without LANA 0.75 beds should be able to operate with this Useable Inventory as its design basis. This will be defined as the Reduced Useable Inventory (RUI) process.

Table 4. Baseline process inventories (g tritium).

\begin{tabular}{|c|c|c|c|c|}
\hline & Separator & $\begin{array}{l}\text { Store } \\
\text { plus } \\
\text { Feed }\end{array}$ & Prod. & Total \\
\hline Hydride & $\mathrm{Pd}$ & $\begin{array}{c}\text { LANA } \\
0.75\end{array}$ & $\begin{array}{c}\text { LANA } \\
0.75\end{array}$ & \\
\hline $\begin{array}{l}\text { Min.: } \\
\text { new }\end{array}$ & 10.0 & 135 & 299 & 444 \\
\hline $\begin{array}{l}\text { Min.: } \\
\text { aged }\end{array}$ & 10.0 & 597 & 1327 & 1934 \\
\hline $\begin{array}{l}\text { Ops: } \\
\text { new }\end{array}$ & 77.3 & 740 & 1645 & 2462 \\
\hline $\begin{array}{l}\text { Ops: } \\
\text { aged }\end{array}$ & 77.3 & 971 & 2159 & 3207 \\
\hline $\begin{array}{l}\text { Useable: } \\
\text { new }\end{array}$ & 135 & 1211 & 2691 & 4037 \\
\hline $\begin{array}{l}\text { Useable: } \\
\text { aged }\end{array}$ & 135 & 749 & 1663 & 2546 \\
\hline Max. & 145 & 1346 & 2990 & 4480 \\
\hline
\end{tabular}

Table 5. Reduced Bed process inventories (g tritium).

\begin{tabular}{cccc}
\hline & Storage & Product & Total \\
\hline $\begin{array}{c}\text { Hydride } \\
\text { Min.: }\end{array}$ & LANA0.75 & LANA0.75 & \\
new & 89.7 & 299 & 389 \\
$\begin{array}{c}\text { Min.: } \\
\text { aged }\end{array}$ & 398 & 1327 & 1725 \\
$\begin{array}{c}\text { Ops: } \\
\text { new }\end{array}$ & 493 & 1645 & 2138 \\
$\begin{array}{c}\text { Ops: } \\
\text { aged }\end{array}$ & 648 & 2159 & 2806 \\
$\begin{array}{c}\text { Useable: } \\
\text { new }\end{array}$ & 807 & 2691 & 3499 \\
$\begin{array}{c}\text { Useable: } \\
\text { aged }\end{array}$ & 499 & 1663 & 2162 \\
Max. & 897 & 2990 & 3887 \\
\hline
\end{tabular}


Aged LANA0.75 beds have a Useable Inventory of 927 STP-L for the Storage and Feed beds, whereas the Product bed Useable Inventory was reduced to 3090 STP-L. The masses of Pd and DU needed for a 927 STP-L Useable Inventory are 13,136 g and 7,722 g, respectively, and for a 3090 STP-L Useable Inventory are 43,786 $\mathrm{g}$ and 25,740 g, respectively. Table 6 shows the minimum and maximum inventories of these reduced Useable Inventory beds. For the RUI process, the Baseline process LANA0.75 beds are replaced with reduced Useable Inventory DU beds. Table 7 shows the results for the RUI process when the Baseline process LANA0.75 beds were replaced with reduced Useable Inventory DU beds.

Table 6. Bed inventories (STP-L) for 927 and 3090 STP-L Useable Inventory beds.

\begin{tabular}{lcc}
\hline & $\mathrm{Pd}$ & $\mathrm{DU}$ \\
\hline $\mathrm{Q} / \mathrm{M}_{\min }: \Delta \mathrm{Q} / \mathrm{M}=927 \mathrm{STP}-\mathrm{L}$ & 69 & 91 \\
$\mathrm{Q} / \mathrm{M}_{\max }: \Delta \mathrm{Q} / \mathrm{M}=927 \mathrm{STP}-\mathrm{L}$ & 996 & 1018 \\
$\mathrm{Q} / \mathrm{M}_{\min }: \Delta \mathrm{Q} / \mathrm{M}=3090 \mathrm{STP}-\mathrm{L}$ & 231 & 303 \\
$\mathrm{Q} / \mathrm{M}_{\max }: \Delta \mathrm{Q} / \mathrm{M}=3090 \mathrm{STP}-\mathrm{L}$ & 3321 & 3393
\end{tabular}

Table 7. Reduced Useable Inventory (RUI) process inventories (g tritium).

\begin{tabular}{ccccc}
\hline & $\begin{array}{c}\text { Separator: } \\
\text { Pd }\end{array}$ & $\begin{array}{c}\text { Store } \\
\text { plus } \\
\text { Feed: } \\
\text { DU }\end{array}$ & $\begin{array}{c}\text { Prod.: } \\
\text { DU }\end{array}$ & Total \\
& & 73 & 163 & 246 \\
Min. & 10 & 748 & 995 & 1520 \\
Ops & 77 & 748 & 1663 & 2546 \\
Useable & 135 & 822 & 1826 & 2793 \\
Max. & 145 & & &
\end{tabular}

\subsection{Minimal process inventories}

As in Section 2.2, relying on alternate process technologies to replace the function of some of the hydride beds can reduce the total number of beds in the process. Eliminating the Separator bed and the Feed bed from the RUI process will be referred to as the Minimal process: the minimal process that can still store feed gas for isotopic separation on hydride beds and also the separated tritium on hydride beds. The removal of the contributions to Table 7 from the Separator and Feed beds produce the results shown in Table 8, which is taken as the Minimal process inventories.

Table 8. Minimal process inventories (g tritium).

\begin{tabular}{cccc}
\hline & Storage & Product & Total \\
\hline Hydride & DU & DU & \\
Min. & 48.9 & 163 & 212 \\
Ops & 298 & 995 & 1293 \\
Useable & 499 & 1663 & 2162 \\
Max. & 548 & 1826 & 2374 \\
\hline
\end{tabular}

\section{Discussion}

The selection of $\mathrm{Q} / \mathrm{M}_{\min }$ and $\mathrm{Q} / \mathrm{M}_{\max }$ values for the different hydride materials was mostly qualitative and these values alone would not be used as hydride material selection criteria. Actual values would be determined based on actual operating process parameters which were beyond the scope of this paper.

The tritium inventory results for the different scenarios presented are summarized in Fig. 4. As anticipated, the tritium induced (aging) effects of LANA0.75 hydride beds produce 1) an increase in the minimum tritium inventory to fill an "empty" process, 2) an increased amount of tritium needed to operate the process, and 3) a reduction in the Useable Inventory of the process. The "Reduced Bed" scenario where the Pdbased Separator beds and the two Feed beds were removed from the Baseline process provides some benefit relative to the minimum facility inventory use of the process inventory; the majority of the tritium is still stored on LANA0.75-based beds, which have a significant amount of inaccessible tritium.

The RUI process scenario, where the Useable Inventory for a DU/Pd bed-based process was set equal to the aged Baseline process Useable Inventory, represents a significant reduction in the minimum inventory of tritium needed in the facility compared to the use of aged LANA0.75 beds. Even though the Baseline process began with a Useable Inventory of $4.037 \mathrm{~kg}$, the Useable Inventory was reduced to $2.546 \mathrm{~kg}$, creating approximately $1.5 \mathrm{~kg}$ of trapped tritium inaccessible by the process.

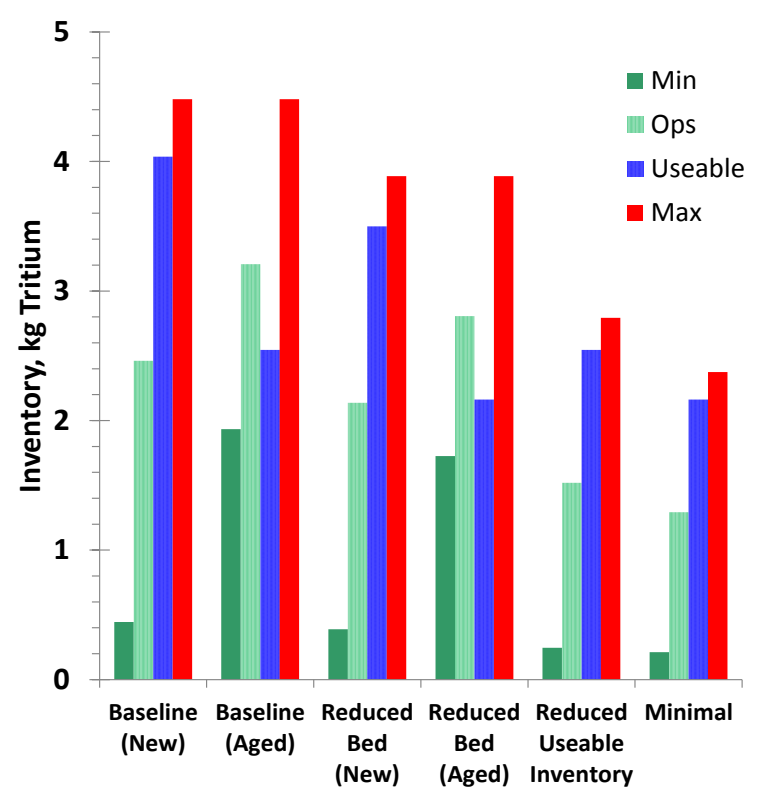

Fig. 4. Process options inventory summary

If minimization of facility inventory is desired, the Minimal process has the removal of additional (Separator and Feed) hydride beds from the RUI process to further decrease facility tritium needs and the amount of tritium that can be released during a DBA. As stated previously, removal of the function of these hydride beds would likely require the addition of other components or processes. A trade study would be needed to determine the cost-benefit of a reduced tritium inventory facility 
with a likely larger glovebox/process equipment footprint and a more compact/smaller footprint facility.

\section{Conclusions}

The use of LANAx alloys offers many advantages for tritium processes, including delivery of He-3 free tritium, the ability to tailor the alloy to exhibit desirable PCT properties, and the use of these beds in a thermal swing absorption-desorption mode to act as vacuum vessels when cooled (absorption) and as pumps when heated (desorption). The major disadvantage of the use of LANAx alloys is the reduced Useable Inventory of these beds as a result of tritium aging effects experienced by the alloy. Even though the Useable Inventory of these LANAx beds is reduced by tritium exposure, the total inventory of these beds is counted as releasable during DBA scenarios. Strategic replacement of LANAx hydride beds with other hydrides, such as Pd or DU, and designing a process with a lower Useable Inventories can significantly reduce facility tritium inventories, but will also require additional process equipment to meet the functional requirements of tritium process operations.

\section{Acknowledgments}

This manuscript has been authorized by Savannah River Nuclear Solutions, LLC under contract No. DEAC09-08SR22470 with the US Department of Energy. The United States Government retains and the publisher, by accepting this article for publication, acknowledges that the United States Government retains a non-exclusive, paid-up, irrevocable, worldwide license to publish or reproduce the published form of this work, or allow others to do so, for United States Government purposes.

\section{References}

[1] M. S. Ortman, T. J. Warren, and D. J. Smith, Use of metal hydrides for handling tritium, Fusion Technol. 8 (1985) 2330-2336.

[2] L. K. Heung, J. H. Owen, R. H. Hsu, R. F. Hashinger, D. E. Ward, and P. E. Bandola, Tritium Confinement in a new tritium processing facility at the Savannah River Site, Fusion Technol. 21 (1992) 594-598.

[3] M. S. Ortman, L. K. Heung, A. Nobile, and R. L. Rabun III, Tritium processing at the Savannah River Site: present and future, J. Vac. Sci. Technol. A 8 (3) May/Jun (1990) 28812889.

[4] H. Diaz, A. Percheron-Guegan, J. C. Achard, C. Chatillon, and J. C. Mathieu, Thermodynamic and structural properties of $\mathrm{LaNi}_{5-\mathrm{y}} \mathrm{Al}_{\mathrm{y}}$ compounds and their related hydrides, Int. J. Hydrogen Energy 4 (1979) 445-454.

[5] A Nobile, J. R. Wermer, and R. T. Walters, Aging effects in palladium and $\mathrm{LaNi}_{4.25} \mathrm{Al}_{0.75}$ Tritides, Fusion Technol. 21 (1992) 769-774.

[6] J. E. Klein, M. K. Mallory, and A. Nobile Jr., Tritium measurement technique using "in-bed" calorimetry, Fusion Technol. 21 (1992) 401-405.

[7] J. E. Klein, A. S. Poore, and D. W. Babineau, Development of fusion fuel cycles: large deviations from US defense program systems, Fusion Eng. Design, 96-97 (2015) 113116.
[8] J. E. Klein, A. S. Poore, X. Xiao, and D. W. Babineau, A new hydrogen processing development system, Fusion Sci. Technol. 68 (2015) 573-577.

[9] R. Li, Y. Sun, Y. Wei, and W. Guo, Aging effects in uranium tritide, Fusion Eng. Design 81 (2006) 859-862. 